\title{
Microcycle conidiation and its genetic basis in Neurospora crassa
}

\author{
RAMESH MAHESHWARI* \\ Department of Biochemistry, Indian Institute of Science, Bangalore 560 012, India and Department of Biological \\ Sciences, Stanford University, Stanford, California 94305-5020, USA
}

(Received 25 February 1991; revised 1 June 1991; accepted 10 June 1991)

\begin{abstract}
Some wild isolates of Neurospora show microcycle conidiation in liquid culture under continuous agitation. Macroconidia from agar-grown mycelial cultures germinated in liquid and the germlings spontaneously produced conidia with no intervening mycelial phase. Three types of microcycle conidiation were seen among progeny of $N$. crassa Vickramam $A \times N$. crassa $a$ wild-type: (1) multinucleate blastoconidia produced by apical budding and septation, (2) multinucleate arthroconidia produced by holothallic septation and disarticulation of cells, and (3) uninucleate microconidia produced directly from conidiogenous cells of the germlings. Two genes were identified which control specific patterns of microcycle conidiogenesis. A single gene $m c b$ in linkage group VR near al-3 (3.2\% recombination) controls blastoconidiation. This gene is epistatic to gene $\mathrm{mcm}$ located in linkage group IIL, very near ro-7 (1.4\%). $\mathrm{mcm}$ controls both microconidiation and arthroconidiation depending on temperature. Strains of genotype $\mathrm{mcm}$ produce microconidia almost exclusively at $18-22^{\circ} \mathrm{C}$, but arthroconidia with few or no microconidia at $30^{\circ} \mathrm{C}$. Because they result in rapid and synchronized conidiation in liquid culture, the two genes should be useful for studies of developmental gene regulation. $\mathrm{mcm}$ makes it possible to obtain large quantities of pure microconidia rapidly for experimentation.
\end{abstract}

\section{Introduction}

Neurospora crassa is a pleomorphic fungus producing three types of vegetative spores from the same mycelium: multinucleate blastoconidia and arthroconidia (collectively called macroconidia), and uninucleate microconidia. Their sequence of development on agar medium, assumed to be uniform in all conidiating species and wild strains, is roughly as follows (Dodge, 1932; Springer \& Yanofsky, 1989). Two to four days after the initiation of growth and the development of a mycelial mat, blastoconidia are produced on branched aerial conidiophores by successive apical budding. They constitute the majority of conidia produced in agar cultures. Approximately $10-12 \mathrm{~h}$ later, extra septa appear in the hyphal region adjacent to the conidiophores. These thicken and undergo separation resulting in the ultimate disarticulation of hyphae into arthroconidia. In 8-10 d, microconidia are produced directly from individual cells of either unbranched or branched microconidiophores which arise from the surface mycelium. This sequence of asexual conidial development is believed to be induced in response to carbon or nitrogen limitation in the medium.

\footnotetext{
* Correspondence should be sent to Bangalore.
}

An abbreviated developmental process, referred to as microcycle conidiation, has been induced in some strains of $N$. crassa under specially manipulated experimental conditions (Cortat \& Turian, 1974; Guignard et al., 1984). In microcycle conidiation, the conidial germlings enter into the asexual reproductive phase without the typical intervening mycelial phase. This phenomenon was first observed by Anderson \& Smith (1971) in submerged conidia of Aspergillus niger which had been exposed to a temperature supraoptimal for growth before incubation at the permissive growth temperature. The thermal treatment caused the conidia to enlarge, and when the temperature was subsequently lowered the conidia produced one or more conidiophores with little or no vegetative mycelium. Synchronized microcycle conidiation in a homogeneous liquid system should provide some major advantages over heterogeneous surface-grown mycelial cultures, enabling specific developmental phases to be obtained in quantity for treatment and study.

Microcycle conidiation has also been described in Penicillium species (Zeidler \& Margalith, 1973; Sekiguchi et al., 1975; Van Gestel, 1983), Paecilomyces variotii (Anderson et al., 1978), Claviceps purpurea (Pazantova et al., 1978), Trichoderma harzianum (Zuber 
\& Turian, 1981) and Acremonium diospyri (Saviour, 1981) as well as in some actinomycetes (Kloepsel \& Ensign, 1984; Daza et al., 1989). The phenomenon has also been reported under the terms 'precocious sporulation' (Boosalis, 1962), 'lag-phase sporogenesis' (Hennessy \& Cantino, 1972), 'premature conidiation' (Cortat \& Turian, 1974) and 'paedogenetic conidiation' (Plesofsky Vig et al., 1983). The key features of microcycle conidiation have been studied in Aspergillus niger by Smith et al. (1981) and in Neurospora crassa by Turian and his associates (Rossier et al., 1977; Ton That \& Turian, 1978; Guignard et al., 1984). In almost all species studied, the phenomenon is inducible by the manipulation of physical and/or chemical conditions of culture and is therefore not an obligatory phase in the life cycle of the organism. Moreover, the process is usually discontinuous since a new batch of conidia prepared through a mycelial culture must be used as inoculum for inducing microcycle conidiation. An exception to this has been reported in Epichloe typhina (Bacon \& Hinton, 1988), but in this case the process was initiated by ascospores rather than conidia. Kølmark (1985) was successful in producing continuous microcycle conidiation mutants in Fusarium solani f. sp. pisi.

$N$. crassa offers many advantages for studying the mechanisms of sporulation, with its huge resource of genetic, molecular and developmental information. Valuable information is available on conidiation (Urey, 1971; Turian \& Bianchi, 1972; Berlin \& Yanofsky, 1985; Springer \& Yanofsky, 1989). A wild isolate of $N$. crassa was found which showed spontaneous microcycle conidiation in liquid medium under constant agitation (Maheshwari, 1989). This strain has been used to derive microcycle-conidiating strains which show specific patterns of conidiogenesis and to identify genes which control conidiogenesis.

\section{Methods}

Strains. Neurospora strains from nature used in this study were either isolated from soil in India (Maheshwari \& Antony, 1974; Palanivelu \& Maheshwari, 1979) or collected from burned substrates in the tropics (Perkins \& Turner, 1988). Standard wild-type strains 74-OR-23-1V A (FGSC 2489) and 74-ORS-6a (FGSC 4200) were provided by the Fungal Genetics Stock Center, Department of Microbiology, University of Kansas Medical Center, Kansas City, Kansas 66103, USA. All linkage testers and mutant marker strains used in this study were from D. D. Perkins, Stanford University, USA (see Perkins et al., 1982).

Species identification of wild strains was made by crossing to species testers recommended by Perkins \& Turner (1988). A few strains were identified as $N$. discreta by crossing them with newly constructed tester strains of this species (R. Maheshwari, unpublished results). All crosses involving wild strains were made on synthetic cross medium (Westergaard \& Mitchell, 1947), incorporating filter paper strips as the sole carbon source.

Liquid cultures. Conidial or ascospore transfers were made on agar slants of minimal or complete medium (Davis \& de Serres, 1970). Cultures were grown at $25-30^{\circ} \mathrm{C}$ until conidia were mature $(7-10 \mathrm{~d})$ as determined by conidial release when gently tapped. A conidial suspension was prepared by adding $1-5 \mathrm{ml}$ of Vogel's $\mathrm{N}$ medium (Vogel, 1964) plus 1.5\%(w/v) glucose to the culture tube and vortexing it vigorously. The suspension was mixed with the above medium to obtain a final volume of $6 \mathrm{ml}$ (in $30 \mathrm{ml}$ vials) or 25 or $50 \mathrm{ml}$ (in 125 or $250 \mathrm{ml}$ Erlenmeyer flasks, respectively). The density of the final conidial suspension was not determined but it was visually comparable to suspensions containing $10^{5}-10^{7}$ conidia $\mathrm{ml}^{-1}$. The cultures were grown on gyratory shakers at 200-240 r.p.m. at the desired temperature for 14-18 h. For examinaton of phenotype, a drop of culture suspension was observed microscopically under low magnification.

Genetic techniques. Culture media, crossing techniques, the procedure for obtaining ascospore progeny, and tetrad analysis were as described by Perkins (1986).

Growth rate. Linear growth rate was measured on minimal agar medium (Vogel, 1964) supplemented with $1.5 \%$ glucose using the tube method of Ryan et al. (1943).

Light microscopy. Unstained samples were mounted in lactophenol and viewed by Nomarski interference optics using a Leitz Ortholux microscope. Samples stained with cotton blue were cleared and mounted in lactophenol. These were viewed and photographed under bright-field illumination using a Leitz or Olympus research microscope.

Fluorescence microscopy. Conidial and germling nuclei were stained using the fluorochrome Hoechst 33258 (Raju, 1982). The stained samples were mounted in a medium containing $90 \mathrm{ml}$ glycerol, $10 \mathrm{ml}$ sodium phosphate buffer (10 mM, pH 7.4), $\mathrm{NaCl}(175 \mathrm{mM})$ and $100 \mathrm{mg}$ p-phenylenediamine to reduce fading (Moens \& Pearlman, 1989). Samples were viewed with a Nikon Microphot FX epifluorescence microscope. Filter combinations were $330-380 \mathrm{~nm}$ excitation, $400 \mathrm{~nm}$ dichroic mirror and $420 \mathrm{~nm}$ barrier. Photographs were taken on Kodak Ektachrome 400 ASA film.

\section{Results}

\section{Microcycle-conidiating strains from natural populations}

Microcycle-conidiating strains of Neurospora were discovered in the course of examining 20 strains from India for variations in colony morphology in submerged liquid cultures grown at $28-30^{\circ} \mathrm{C}$ for $16-24 \mathrm{~h}$. The majority of strains produced either thick suspensions or clumped mycelia composed of vegetative hyphae. In contrast, $N$. crassa from Vickramam and $N$. discreta from Bandipur (Table 1) produced thin homogeneous suspensions resembling a culture of bacteria rather than a filamentous fungus. The submerged conidia of strains Vickramam (Maheshwari, 1989) and Bandipur (Fig. 1) had bypassed the mycelial phase and prematurely differentiated asexual spores (microcycle conidiation). Timecourse examination by light microscopy showed that the polarized growth of the conidial germ tube had become arrested. This was followed by multiple septation along the length of the germ tube, enlargement of cells, thickening of cross-walls, formation of disjunctor cells and eventual fragmentation of the chain of conidia. The 
Table 1. Strains of Neurospora from nature showing microcycle conidiation

Conidia of all strains were grown for $24 \mathrm{~h}$ at $22{ }^{\circ} \mathrm{C}$, with agitation, in Vogel's $\mathrm{N}$ medium supplemented with $1.5 \%$ glucose.

\begin{tabular}{|c|c|c|c|c|c|c|}
\hline \multirow{2}{*}{$\begin{array}{l}\text { Strain and } \\
\text { mating type }\end{array}$} & \multirow[b]{2}{*}{ Species } & \multirow[b]{2}{*}{ Substrate } & \multirow[b]{2}{*}{ Country } & \multirow{2}{*}{$\begin{array}{c}\text { FGSC } \\
\text { no. }\end{array}$} & \multicolumn{2}{|c|}{ Type of conidia produced* } \\
\hline & & & & & Macroconidia & Microconidia \\
\hline Vickramam $A$ & N. crassa & Soil & India & 6688 & + & - \\
\hline Bandipur $a$ & N. discreta & Soil & India & 6789 & + & - \\
\hline Bangalore $1989-10 \mathrm{~A}$ & $N$. sitophila & Soil & India & & + & + \\
\hline P1859 $A$ & $N$. discreta & Burnt vegetation & Papua New Guinea & 6785 & + & - \\
\hline $\mathrm{P} 1913 A$ & N. discreta & Burnt vegetation & Papua New Guinea & 6786 & + & - \\
\hline $\mathrm{P} 1992 A$ & N. discreta & Burnt vegetation & Papua New Guinea & 6788 & + & - \\
\hline P3002 a & N. discreta & Burnt vegetation & Thailand & 6790 & + & - \\
\hline $\mathrm{P} 3003 a$ & N. discreta & Burnt vegetation & Thailand & & + & - \\
\hline P3004 a & N. discreta & Burnt vegetation & Thailand & 6791 & + & - \\
\hline P3016 a & N. discreta & Burnt vegetation & Thailand & 6792 & + & - \\
\hline P3726 $\mathrm{A}$ & $N$. crassa & Burnt vegetation & Ivory Coast & 4830 & + & - \\
\hline P4342a & N. sitophila & Steamed sawdust & Thailand & 6805 & + & + \\
\hline
\end{tabular}

* + and - indicate presence or absence of conidia, respectively.

morphological unit comprising the parent conidium and the unbranched or sparsely branched conidial germ tube bearing asexual spores is hereafter referred to as a microcycle structure.

A total of 114 Neurospora strains from different geographical regions were scored for microcycle phenotype. Three conidiating (heterothallic) species were included in this study. Twelve strains showed microcycle development (Table 1) with significant phenotypic differences in the branching of microcycle structure, enlargement of conidia and disjunctor cells.

In several strains, notably Vickramam, Bandipur, Bangalore 1989-10 and P1913 some cells in the microcycle structure oozed out protoplasm and became empty (Fig. 1e). Such cells were present in exceptionally high numbers in 36-48 h cultures of strains Vickramam and Bandipur. It is not clear whether these cells facilitate the disarticulation of the chain of conidia.

Considerable variation existed in the enlargement of conidial cells in microcycle structure. In Vickramam, the conidia became exceptionally enlarged by $48 \mathrm{~h}$, attaining a diameter of $25 \mu \mathrm{m}$. Although the common pattern of conidiogenesis was by an arthric process, in a few strains a phialidic process of conidiogenesis (Turian, 1976; Cole, 1986) was also observed in which the microcycle structures had vacuolated cells bearing microconidialike structures. This type of conidiogenesis was observed at $22{ }^{\circ} \mathrm{C}$ in $5-10 \%$ of germinated conidia in strains $\mathrm{P} 3002$ and $\mathrm{P} 3003$, and in $35 \%$ of germinated conidia in P4342.

\section{Aerial versus microcycle conidiation}

In mycelial cultures, grown either on agar or on liquid in stationary flasks, the conidiophores produced from aerial hyphae of Vickramam or Bandipur were branched structures as in wild-type Neurospora. These conidiophores produced macroconidia (blastoconidia) by a process of successive apical budding (Fig. 2).

In agitated liquid cultures, the morphology of microcycle structures of strains Vickramam and Bandipur was so different that they might not be recognized as belonging to Neurospora. The microcycle structures were either unbranched or very sparsely branched. Macroconidia were produced chiefly by septation and disarticulation of germ tubes (arthroconidiation). To determine if they were viable, the microcycle structures were transferred onto agar medium. The conidial cells in the microcycle structures germinated rapidly (Fig. 2c). By contrast, their in situ germination in liquid medium was poor. Submerged germinated conidia were present in low numbers but these are thought to have been those which had contacted the surface and initiated development before being swept back into the liquid. A ring of mycelium was usually present on the wall of the flask at the liquid-air interface.

Microcycle conidiation was a discontinuous process. A new batch of conidia had to be prepared from a mycelial culture for repetition of the cycle.

\section{Inheritance of the microcycle conidiation phenotype}

Vickramam $A$ was crossed to wild-type 74-ORS-6a. Randomly isolated ascospores showed up to $70 \%$ germination. About $10 \%$ of the resultant progeny conidiated poorly or were aconidiate and these were discarded. Conidia were incubated in liquid medium on a shaker. The progeny showed variations of phenotype. Some progeny cultures produced homogeneous growth of low density which settled down in the culture flask. The 

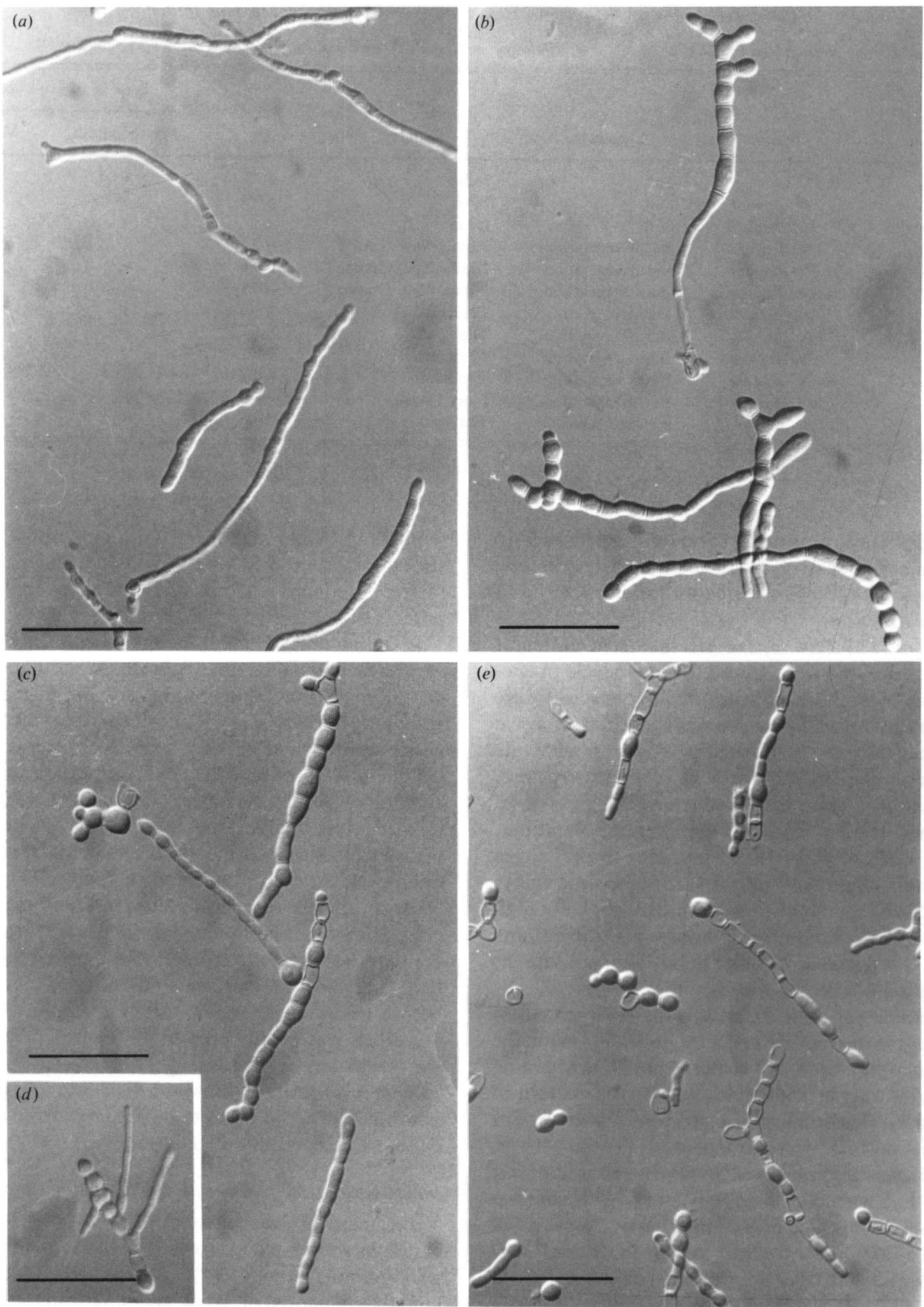

Fig. 1. Microcycle conidiation in N. discreta Bandipur $a$. All micrographs were obtained using Nomarski-interference optics. (a) $12 \mathrm{~h}$. Transverse basipetal septations in the conidial germ tube have occurred. $(b) 18 \mathrm{~h}$. Cross walls have thickened and individual arthroconidial cells have enlarged. (c) $24 \mathrm{~h}$. Emptied disjunctor cells have been formed in rows of arthroconidia. (d) $24 \mathrm{~h}$. A microcycle structure showing in situ germination of arthroconidia. (e) $48 \mathrm{~h}$. Disarticulation of arthroconidia. Bars, $50 \mu \mathrm{m}$. 

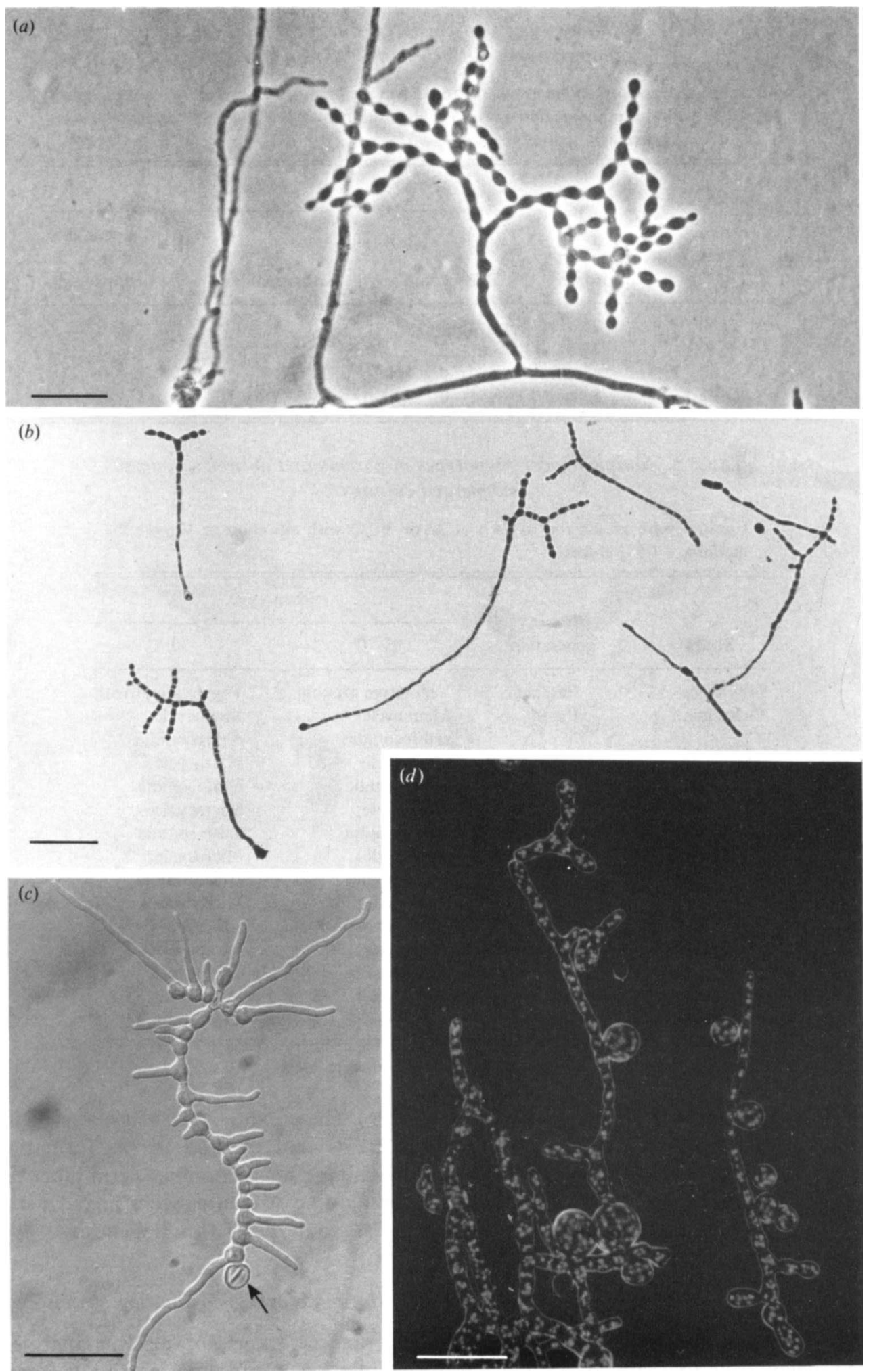

Fig. 2. Conidiation in $N$. crassa Vickramam $A$. (a) Surface development $(48 \mathrm{~h})$ on a dialysis membrane placed over the agar medium, showing a portion of vegetative growth and an aerial conidiophore $(48 \mathrm{~h})$. Phase-contrast microscopy. Bar, $: 25 \mu \mathrm{m}$. (b) Microcycle conidiation in submerged culture $(14 \mathrm{~h})$. Photomicrograph of a sample stained with cotton blue. Bar, $50 \mu \mathrm{m}$. $(c)$ Germination of arthroconidia in a microcycling structure transferred from submerged culture $(14 \mathrm{~h})$ to a dialysis membrane placed over the agar medium $(5 \mathrm{~h})$. Arrow shows parent conidium. Phase-contrast microscopy. Bar, $50 \mu \mathrm{m}$. (d) Combined dark-field and fluorescence image of microcycle structures showing multinucleate conidia. Bar, $25 \mu \mathrm{m}$. 
Table 2. Numbers of different conidial phenotypes in microcycle-conidiating progeny obtained from 74-ORS-6a $\times$ Vickramam $A$

Conidia of progeny cultures were grown for $16-18 \mathrm{~h}$ at the specified temperature with agitation in Vogel's $\mathrm{N}$ medium supplemented with $1.5 \%$ glucose. In crosses 2 and 3, Vickramam $A$ was used as the protoperithecial parent.

\begin{tabular}{cccccc}
\hline \hline & & & \multicolumn{3}{c}{ Conidial phenotype } \\
\cline { 3 - 6 } Cross & $\begin{array}{c}\text { Assay } \\
\text { temp. } \\
\text { no. }\end{array}$ & $\begin{array}{c}\text { Total no. } \\
\text { of } \mathrm{C})\end{array}$ & Blastoconidia & Arthroconidia & $\begin{array}{c}\text { Microconidia } \\
\text { or microconidia } \\
+ \text { arthroconidia }\end{array}$ \\
\hline 1 & 30 & 26 & 2 & 4 & 0 \\
2 & 30 & 25 & 0 & 9 & 0 \\
3 & 30 & 47 & 0 & 14 & 0 \\
4 & 22 & 55 & 0 & 6 & 10 \\
\hline \hline
\end{tabular}

Table 3. Morphological phenotypes of parents and derived strains in submerged cultures

Conidia were grown for $16-24 \mathrm{~h}$ at 22 or $30^{\circ} \mathrm{C}$ with agitation in Vogel's $\mathrm{N}$ medium $+1.5 \%$ glucose.

\begin{tabular}{|c|c|c|c|}
\hline \multirow[b]{2}{*}{ Strain } & \multirow{2}{*}{$\begin{array}{l}\text { Progeny } \\
\text { generation }\end{array}$} & \multicolumn{2}{|c|}{ Phenotype } \\
\hline & & $22{ }^{\circ} \mathrm{C}$ & $30^{\circ} \mathrm{C}$ \\
\hline 74-ORS-6a & Parent & Vegetative growth & Vegetative growth \\
\hline Vickramam $A$ & Parent & $\begin{array}{l}\text { Microcycle; } \\
\text { arthroconidia }\end{array}$ & $\begin{array}{l}\text { Microcycle; } \\
\text { arthroconidia }\end{array}$ \\
\hline $\operatorname{RM} 1-3 A^{*}$ & $f_{5}$ & $\begin{array}{l}\text { Microcycle; } \\
\text { blastoconidia }\end{array}$ & $\begin{array}{l}\text { Microcycle; } \\
\text { blastoconidia }\end{array}$ \\
\hline RM $1-9 a^{*}$ & $\mathrm{f}_{5}$ & $\begin{array}{l}\text { Microcycle; } \\
\text { blastoconidia }\end{array}$ & $\begin{array}{l}\text { Microcycle; } \\
\text { blastoconidia }\end{array}$ \\
\hline RM 5-1 $a^{\dagger}$ & $f_{5}$ & $\begin{array}{l}\text { Microcycle; } \\
\text { microconidia }\end{array}$ & $\begin{array}{l}\text { Microcycle; } \\
\text { arthroconidia }\end{array}$ \\
\hline RM 5-21 $A \dagger$ & $f_{5}$ & $\begin{array}{l}\text { Microcycle; } \\
\text { microconidia }\end{array}$ & $\begin{array}{l}\text { Microcycle; } \\
\text { arthroconidia }\end{array}$ \\
\hline RM 39-6a† & $f_{6}$ & $\begin{array}{l}\text { Microcycle; } \\
\text { microconidia }\end{array}$ & $\begin{array}{l}\text { Microcycle; } \\
\text { arthroconidia }\end{array}$ \\
\hline RM $39-8 A^{\dagger}$ & $\mathrm{f}_{6}$ & $\begin{array}{l}\text { Microcycle; } \\
\text { microconidia }\end{array}$ & $\begin{array}{l}\text { Microcycle; } \\
\text { arthroconidia }\end{array}$ \\
\hline
\end{tabular}

* Genotype $m c b$.

short germ tubes had differentiated structures resembling asexual spores. Although none of this set of progeny cultures possessed a phenotype exactly like Vickramam, their development was unambiguously microcyclic. A set of progeny grew as dispersed cultures of intermediate density. The germ tubes were longer and had differentiated conidiophore-like structures at their apical ends. Yet another set of progeny cultures produced clumped mycelial growth of high density.

In a total of 153 progeny from four crosses, 45 showed microcycle conidiation (Table 2). The predominant pattern of conidiogenesis was of the arthric type, resembling the parent strain Vickramam. In addition, new conidial phenotypes appeared in the progeny. These conformed to the blastic and the phialidic types (Turian,
† Genotype mom.

1976). The phialidic type was observed in cultures grown at $22{ }^{\circ} \mathrm{C}$ and resulted in the formation of structures resembling microconidia. Germ tubes producing microconidia-like structures were mixed with those showing the arthric type of conidiogenesis.

\section{Derived microcycle conidiating strains}

To obtain strains for genetic analysis of microcycle conidiation, representative progeny cultures from 74ORS- $6 a \times$ Vickramam $A$ showing different conidial phenotypes (blastoconidia or arthroconidia) were selected and purified by backcrossing to the Oak Ridge wild-type. Characteristics of the derived strains are shown in Table 3. 

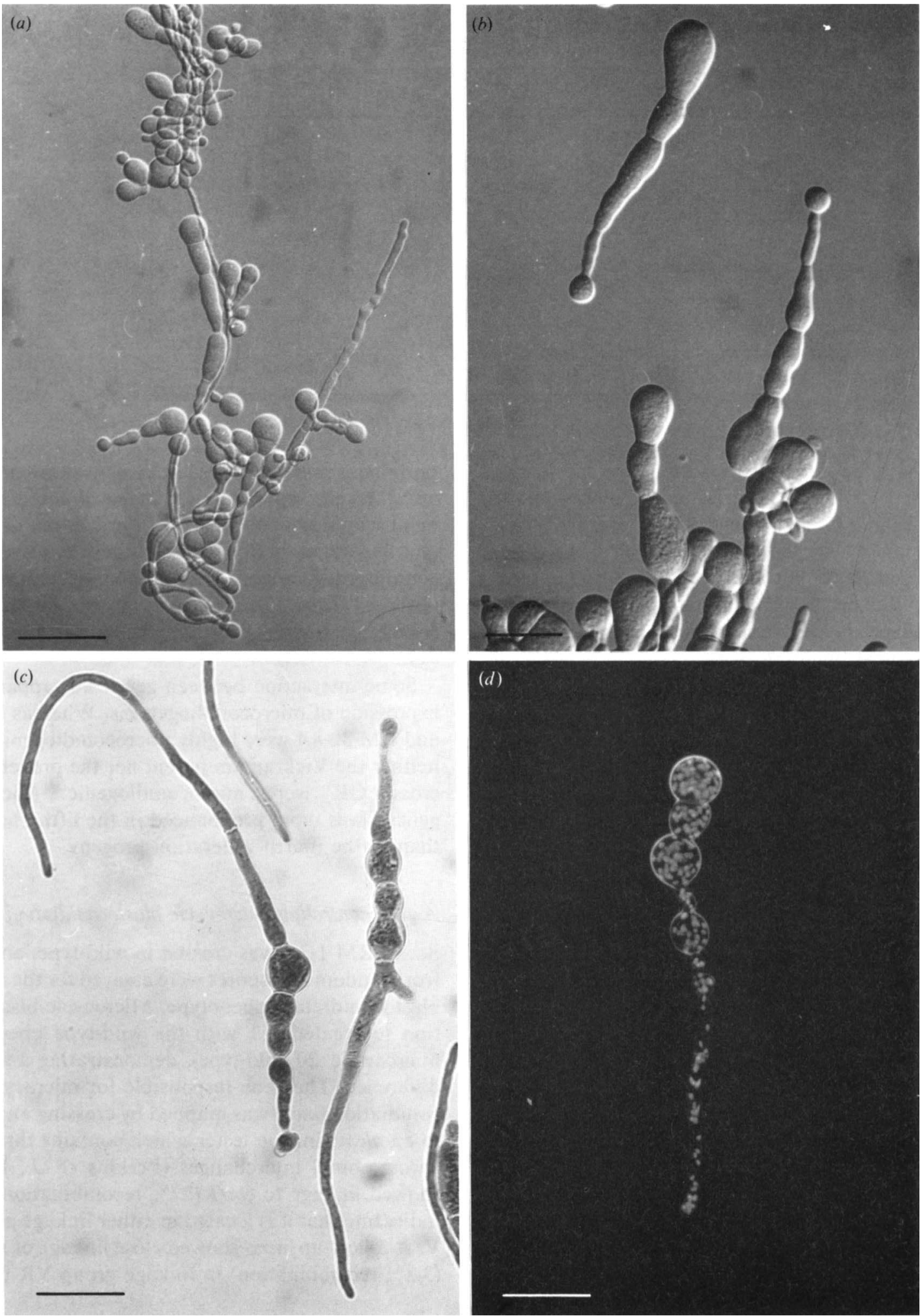

Fig. 3. Microcycle blastoconidiation in $m c b$ (RM 1-3A). (a) Nomarski-interference image of microcycle structures (12 h). Swollen conidia have been formed by the process of apical budding. Bar, $50 \mu \mathrm{m}$. (b) Magnified view of $(a)$. Bar, $25 \mu \mathrm{m}$. (c) Bright-field image of a cotton-blue-stained microcycle structure $(14 \mathrm{~h})$ in which apical blastoconidia have reverted to hyphal growth. Bar, $25 \mu \mathrm{m}$. (d) Combined dark-field and fluorescence image of multinucleate blastoconidia stained with Hoechst 33258. Bar, $25 \mu \mathrm{m}$. 
Table 4. Linkage in cross cot-1;al-3 $a \times m c b$ RMI-3 A

cot-l is in linkage group IVR. $a l-3$ is in VR.

\begin{tabular}{|c|c|c|c|c|}
\hline Progeny & \multicolumn{3}{|c|}{ Genotype } & No. \\
\hline \multirow{5}{*}{$a l-3-m c b$ non-crossovers } & + & + & $m c b$ & 41 \\
\hline & $\cot$ & $a l$ & + & 40 \\
\hline & + & $a l$ & + & 39 \\
\hline & $\cot$ & + & $m c b$ & 31 \\
\hline & $\int \cot$ & + & + & 2 \\
\hline \multirow{3}{*}{$a l-3-m c b$ crossovers } & + & $a l$ & $m c b$ & 1 \\
\hline & + & + & + & 1 \\
\hline & cot & $a l$ & $m c b$ & 1 \\
\hline \multirow{2}{*}{\multicolumn{4}{|c|}{$\begin{array}{l}\text { Total } \\
\text { Recombination frequency: } c o t \text { and } m c b=47 \% \\
\qquad a l \text { and } m c b=3 \cdot 2 \%\end{array}$}} & 156 \\
\hline & & & & \\
\hline
\end{tabular}

Strain RM 1-3A differed from the wild-type in two clearly defined ways. First, it grew more slowly than the wild-type: $2 \cdot 2 \mathrm{~mm} \mathrm{~h}^{-1}$ on agar medium at $34^{\circ} \mathrm{C}$ compared to $5.0 \mathrm{~mm} \mathrm{~h}^{-1}$ for the wild-type. Growth was faster $\left(3.0 \mathrm{~mm} \mathrm{~h}^{-1}\right)$ at $25^{\circ} \mathrm{C}$ but still less than the wild-type. Second, in shaken liquid cultures, the germinating macroconidia produced a series of multinucleate cells by successive apical budding with septa appearing at positions of constrictions (Fig. 3). This pattern of development was analogous to that of blastoconidia produced by aerial hyphae in agar-grown cultures of wild-type $N$. crassa (Springer \& Yanofsky, 1989). Therefore, RM 1-3A was considered a microcycle blastoconidiating strain. However, unlike the blastoconidia produced by aerial hyphae, those produced in submerged cultures were swollen and were not observed to separate. Sometimes the terminal or the basal cell showed a tendency to revert to hyphal growth.

Strains RM 5-21 $A$ and RM 39-8 $A$ produced microconidia (Fig. 4) or arthroconidia (Fig. 5), depending on the culture temperature. Their growth rate on agar medium was indistinguishable from the wild-type. In submerged cultures at $22^{\circ} \mathrm{C}$, the cells in the unbranched or the sparsely branched microcycling structures abstricted small spherical or ovoid uninucleate cells. Beginning 14-18 h after the initiation of the culture, such cells were produced in great abundance; up to $10^{7}$ cells $\mathrm{ml}^{-1}$ could be obtained in $24 \mathrm{~h}$. These cells were comparable to microconidia of the peach fluffy ( $p e f$ ) and fluffy dingy $(f l ; n)$ mutant strains of $N$. crassa in ontogeny, size, shape and nuclear number and were therefore regarded as microconidia. The microconidia produced in the microcycle system, like those produced by $p e f l$ and $f ; d n$, were greenish-brown.

By contrast, when RM 5-21 $A$ or RM 39-8 $A$ were grown at $30^{\circ} \mathrm{C}$ differentiation of microconidia was nearly completely suppressed. The germ tube hyphae showed prominent septa in $12 \mathrm{~h}$. The cross-walls then thickened and the cells separated. This type of conidial development was similar to that of arthroconidia as described and illustrated by Springer \& Yanofsky (1989). Arthroconidiogenesis and microconidiogenesis were sometimes observed at $22{ }^{\circ} \mathrm{C}$ in microcycling structures produced from opposite sides of same germinating conidium (Fig. $5 c$ ).

Some interaction between genes was apparent in the expression of microconidiogenesis. Whereas RM 5-21 A and RM 39-8 $A$ were highly microconidiogenic at $22^{\circ} \mathrm{C}$, neither the Vickramam parent nor the progeny from its cross $\times$ OR were microconidiogenic. Microconidiogenesis was more pronounced in the fifth and the sixth than in the fourth generation progeny.

\section{A gene controlling microcycle blastoconidiation}

Strain RM 1-3A was crossed to wild-type, and progeny from random ascospores were assayed for the microcycle blastoconidiation phenotype. Microcycle blastoconidiation segregated $1: 1$ with the wild-type phenotype (23 microcyclic: 20 wild-type), demonstrating a single gene difference. The gene responsible for microcycle blastoconidiation ( $m c b$ ) was mapped by crossing an $m c b$ strain to an alcoy linkage tester which contains three marked chromosomal interchanges (Perkins et al., 1969). mcb showed linkage to cot- 1 ( $27 \%$ recombination) in alcoy, indicating that it is located in either linkage group IV or $\mathrm{V}$. A follow-up cross showed close linkage of $m c b$ to $a l-3$ $(3 \cdot 2 \%$ recombination) in linkage group VR (Table 4$)$.

\section{A gene controlling microcycle microconidiation and microcycle arthroconidiation, depending on temperature}

To resolve whether the temperature-dependent switch in production between microconidia and arthroconidia was 

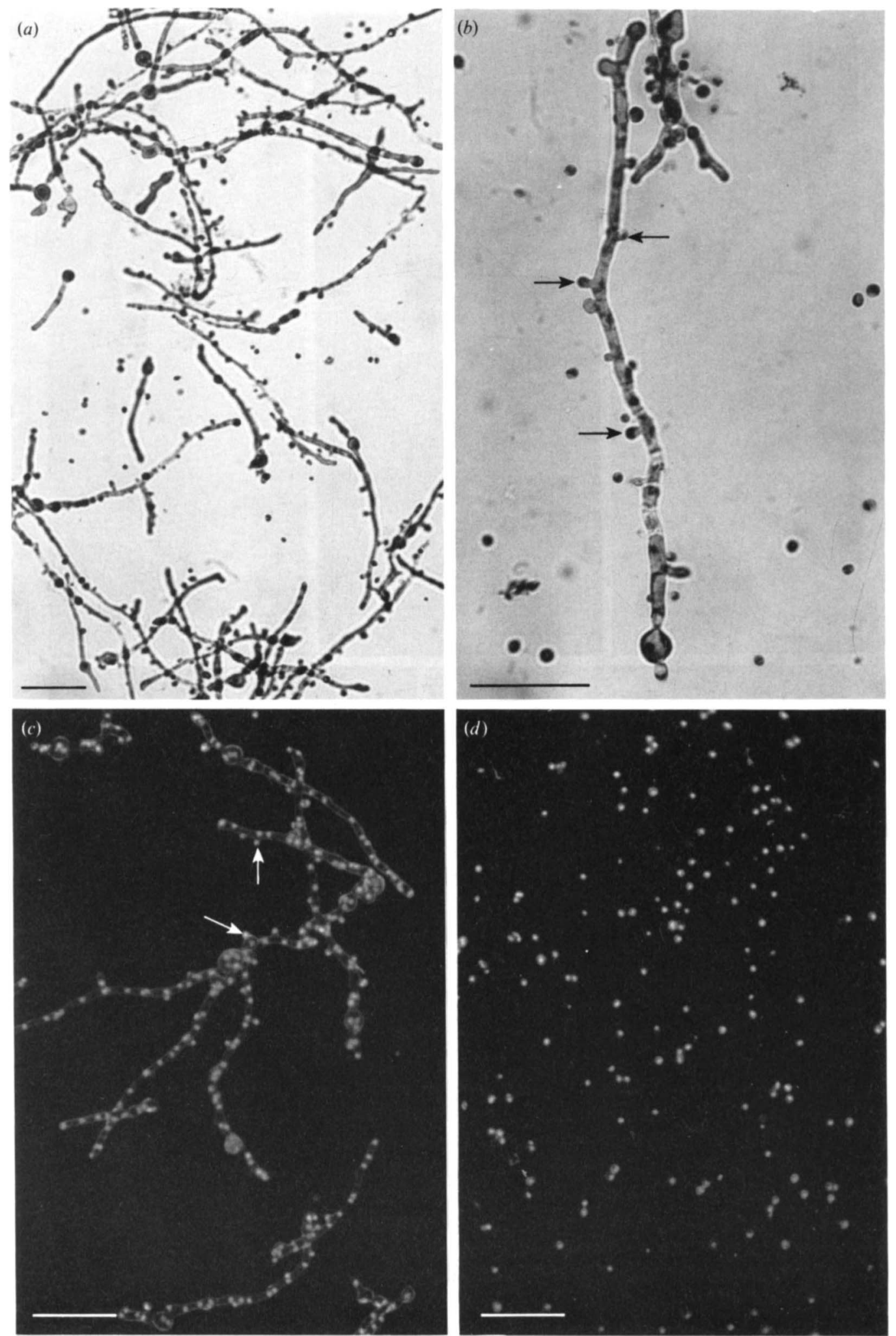

Fig. 4. Microcycle microconidiation in $m c m\left(\operatorname{RM~39-8A)}\right.$ at $22^{\circ} \mathrm{C}$. (a) Bright-field image of a cotton-blue-stained culture (18 h) $(b)$ Close-up of a microcycle structure showing production of microconidia as lateral protuberances (arrows). Free microconidia are present. (c) Combined dark-field and fluorescence image of microcycle structure showing microconidiogenesis (arrows). (d) Fluorescence image of predominantly uninucleate microconidia stained with Hoechst 33258 . Bars, $25 \mu \mathrm{m}$. 

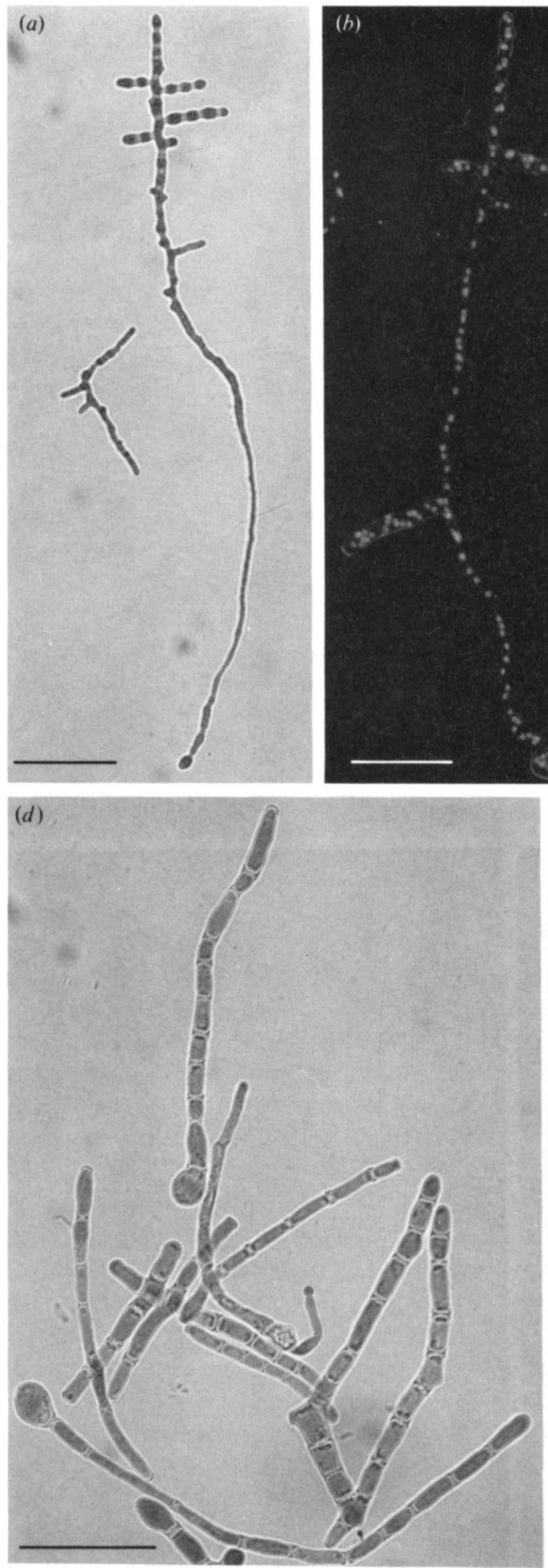
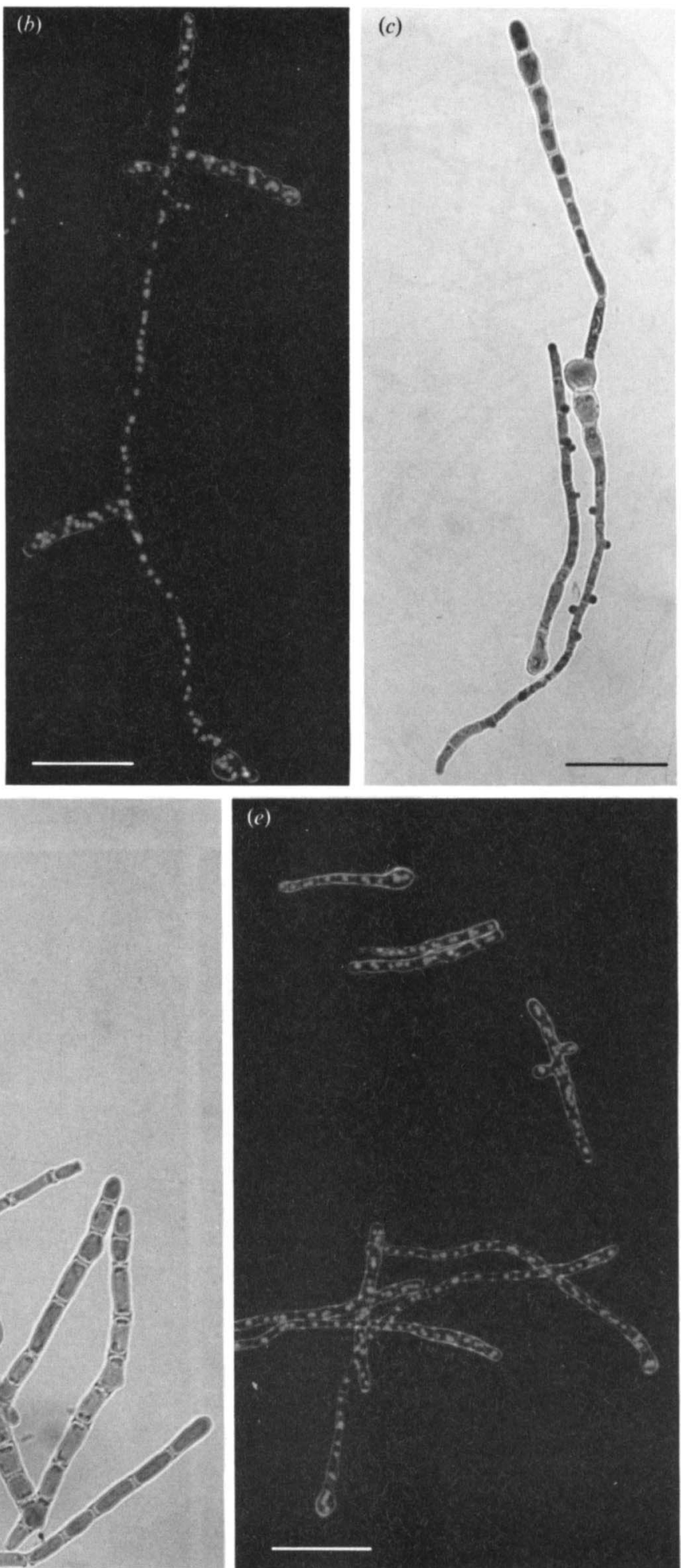

Fig. 5. Microcycle arthroconidiation in $m c m$ (RM 39-8A) at $30^{\circ} \mathrm{C}$. (a) Photomicrograph of a microcycle structure (14 h) stained with cotton blue. (b) A microcycle structure showing multinucleate arthroconidial cells visualized by fluorescent staining. (c) An example of microconidiogenesis and arthroconidiogenesis at $22^{\circ} \mathrm{C}$ in microcycling structures produced from opposite sides of a single conidium $(14 \mathrm{~h})$. Bright-field micrograph of cotton blue-stained sample. $(d)$ Bright-field image of a cotton-blue-stained $18 \mathrm{~h}$ culture showing thickened septa and disarticulation of hyphal cells. $(e)$ Multinucleate disarticulated hyphal fragments $(18 \mathrm{~h})$ visualized by combined dark-field and fluorescence microscopy. Bars, $25 \mu \mathrm{m}$. 
Table 5. Linkage in cross ro-7 rip a $\times$ mcm $R M$ 39-8 A

ro-7 is at the left end of linkage group II; rip is at the right end.

\begin{tabular}{|c|c|c|c|c|}
\hline Progeny & \multicolumn{3}{|c|}{ Genotype } & No. \\
\hline \multirow{4}{*}{ ro-7-mcm non-crossovers } & + & $\mathrm{mcm}$ & + & 12 \\
\hline & ro-7 & + & rip & 23 \\
\hline & + & $m c m$ & rip & 17 \\
\hline & ro-7 & + & + & 21 \\
\hline ro-7-mcm crossover & + & + & + & 1 \\
\hline \multirow{2}{*}{\multicolumn{4}{|c|}{$\begin{array}{l}\text { Total } \\
\text { Recombination frequency: } r o-7 \text { and } m c m=1.4 \% \\
\qquad \text { rip and } m c m=52.7 \%\end{array}$}} & 74 \\
\hline & & & & \\
\hline
\end{tabular}

due to a single gene, RM 39-8 $A$ was crossed to wild-type 74-ORS-6a. Four groups of eight shot ascospores (unordered tetrads) were collected and the phenotypes of progeny cultures were determined in shaken cultures at both 22 and $30^{\circ} \mathrm{C}$. The microcycle and the wild-type phenotypes showed 1:1 segregation. All microcycleconidiating cultures which produced microconidia at the lower temperature differentiated arthroconidia at the higher temperature, suggesting that the two patterns of conidiogenesis are controlled by a single gene. The results demonstrated that a single gene, designated $\mathrm{mcm}$, controls both microconidiation and arthroconidiation, the switch determining the conidiogenic pathway being dependent on the temperature of incubation.

In crosses with the linkage tester (alcoy;csp-l or alcoy), $\mathrm{mcm}$ showed nearly $50 \%$ recombination with all linkage markers (data not shown). This indicated that $\mathrm{mcm}$ is located towards the end of one of the chromosome arms. A distal location of $\mathrm{mcm}$ was confirmed by crossing the $\mathrm{mcm}$ microcycle strain to spore killer testers (Perkins et al., 1986). Second-division segregation of $\mathrm{mcm}$ attained a frequency of $65 \%$ in crosses with $S k-2^{\mathrm{K}}$ (data not shown). Based on the above information $\mathrm{mcm}$ was crossed to linkage testers bearing distal markers. $\mathrm{mcm}$ was subsequently located in linkage group IIL, very close to ro-7 $(1.4 \%$ recombination) (Table 5$)$.

\section{Interaction between $\mathrm{mcb}$ and $\mathrm{mcm}$}

To study the interaction of the non-allelic genes $m c b$ and $\mathrm{mcm}$, unordered tetrads from 17 asci were isolated from the cross $m c b \times m c m$. The ascus types obtained were 3 parental ditypes (PD), 3 nonparental ditypes (NPD) and 11 tetratypes (T). The NPD class showed wild-type and microcycle blastoconidiation phenotypes in equal frequency. As the genotype $m c b ; m c m$ produced only blastoconidia in liquid shake cultures at 22 or $30^{\circ} \mathrm{C}$, it was inferred that $m c b$ is epistatic to $\mathrm{mcm}$.

\section{Discussion}

The present work documents the existence of microcycleconidiation strains of Neurospora which sporulate precociously in liquid medium under continuous agitation. Microcycle conidiation has been considered an artificial system (Dahlberg \& Van Etten, 1982), there being no natural role for this event. However, the reported occurrence of this phenomenon in several fungi in response to cultural manipulations (Smith et al., 1981) and the finding that a single gene can mediate the transition from vegetative growth to sporulation in naturally occurring fungi (Adams et al., 1988; this study) in response to an environmental signal suggests that microcycle conidiation may have a role in nature. This mode of development will allow fungi to reproduce in the briefest possible time. It may be a facultative developmental capability in some fungi which is expressed in response to as yet uncharacterized signals.

Is the microcycle conidiation a telescoped version of the normal conidiation in aerial hyphae or do the two differentiation proceses represent independent developmental pathways? The two processes may be compared with respect to the patterns and order of conidiogenesis and the cultural conditions under which they occur.

Microcycle conidiation in the wild strains differs from normal conidiation by being primarily arthroconidiogenic, by early conidiation (12-14 h) and by occurring when nutrients are not limiting. Moreover, a single microcycle structure generally showed a single conidial phenotype. More striking were the similarities in conidial ontogeny and in nuclear behaviour in the two modes of conidiation under consideration. It is yet to be demonstrated, however, whether genes differentially expressed during aerial conidiogenesis (Berlin \& Yanofsky, 1985) correspond to those which are expressed during microcycle conidiation. 
The majority of ascospores produced in crosses of Vickramam to $N$. crassa wild-type were viable. The appearance of new conidial phenotypes among the microcycle conidiating progeny in backcrosses of Vickramam to wild-type showed that more than a single gene is involved in the control of microcycle conidiation phenotype. The number of microcycle-conidiating progeny recovered in $\mathrm{f}_{1}$ with blastoconidial phenotype was significantly less than those with arthroconidial/microconidial phenotype. It was shown that the gene $m c b$ produces blastoconidia whereas $\mathrm{mcm}$ produces microconidia or arthroconidia depending upon incubation temperature. Appearance of the blastoconidial phenotype in $f_{1}$ progeny may be explained by assuming an interaction of $m c b$ with a linked suppressor gene, $s u$. Thus the parent strain, Vickramam, which produces microcycle structures showing arthroconidiation and not blastoconidiation, has the approximate genotype $m c m ; m c b s u$. Only segregants having genotype $m c b$ or $m c m ; m c b$ produce blastoconidia. It was not possible to differentiate phenotypically between $m c b$ and $m c m ; m c b$ because of epistasis of $m c b$. A strain with genotype $m c m ; m c b s u$ in which blastoconidiation is suppresed is arthroconidiogenic/microconidiogenic, depending on growth temperature.

Complex gene-interaction was also indicated in the control of microcycle microconidiation. Regardless of the temperature of cultivation, production of microconidia did not occur in microcycle structures of Vickramam, although they were produced in backcrossed progeny. Since their numbers increased in successive backcrosses to the wild-type, $\mathrm{mcm}$ appears to be quantitatively affected by modifier genes. Such an impression was also gained from crosses of $\mathrm{mcm}$ to several strains with marker loci during attempts to map the locus, $\mathrm{mcm}$ being difficult to score in some genetic backgrounds.

Whether the microcycle-conidiating strain produced microconidia or arthroconidia appeared to depend on a switch mechanism in which incubation temperature was important. A temperature-dependent switch in conidial phenotype was first reported by Grigg (1960) who found that $N$. crassa mutant $\mathrm{col}-1 ; \mathrm{m}$ is microconidiate at $25^{\circ} \mathrm{C}$ and macroconidiate at $35^{\circ} \mathrm{C}$. A similar observation was made by Guignard et al. (1984) in St Lawrence STA (FGSC no. 262) and Lindegren 1A (FGSC no. 354) strains in which microcycle conidiation was induced by nitrogen limitation.

A simple explanation for the action of the genes $m c b$ and $\mathrm{mcm}$ is that they are master regulatory genes which ensure the proper timing of expression of groups of conidiation-specific structural genes whose products all act within a developmental pathway. The controlling genes presumably respond to specific environmental parameters such as $\mathrm{pH}$, temperature, nutrient type and concentration. Such an envisaged function of $m c b$ and mcm fits the definition of homeotic genes (Gehring, 1987).

The microcycle-conidiating strains $m c b$ and $m c m$ derived from Vickramam in the Oak Ridge wild-type $N$. crassa background have promise as research tools. In contrast to the mixed population of conidial types in agar-grown cultures of most laboratory strains, the microcycle-conidiating strains enable the exclusive production of any of the desired type of conidia in relatively large quantity with a high degree of synchrony in the short time of 12-24 h. This suggests the usefulness of the microcycle-conidiating strains in studies of developmental gene regulation. The strain of $\mathrm{mcm}$ genotype offers a rapid and clean way of obtaining large numbers of pure microconidia for genetic and biochemical experimentation. The relatively high germinability of these microconidia (up to $35 \%$; unpublished results) should facilitate the production and detection of mutations. The strains have high fertility in crosses, and desired markers can be introduced. The ability to produce microconidia exclusively should prove valuable in genetic transformation studies.

I thank the University Grants Commission, New Delhi, and Council for International Exchange of Scholars, Washington, DC, USA, for the award of a Fulbright fellowship which enabled me to complete this work in the laboratory of David D. Perkins at Stanford University. I am indebted to him for advice, help and encouragement during the study. I thank David Perkins, N. B. Raju, David Jacobson and Dorothy Newmeyer for help in preparation of the manuscript. This work was supported by a grant from the University Grants Commission at Bangalore and by Public Health Service Research Grant AI-01462 at Stanford.

\section{References}

Adams, T. H., Boylan, M. T. \& Timberlake, W. E. (1988). brl $A$ is necessary and sufficient to direct conidiophore development in Aspergillus nidulans. Cell 54, 353-362.

ANDERSON, J. G. \& SMITH, J. E. (1971). The production of conidiophores and conidia by newly germinated conidia of Aspergillus niger (microcycle conidiation). Journal of General Microbiology 69, 185-197.

Anderson, J. G., Aryee, V. \& Smith, J. E. (1978). Microcycle conidiation in Paecilomyces variotii. FEMS Microbiology Letters 3, 57-60.

BaCON, C. W. \& Hinton, D. M. (1988). Ascosporic iterative germination in Epichloe typhina. Transactions of the British $\mathrm{Myco-}$ logical Society 90, 563-569.

BERLIN, V. \& YANOFSKY, C. (1985). Isolation and characterization of genes differentially expressed during conidiation of Neurospora crassa. Molecular and Cellular Biology 5, 845-855.

Boosalis, M. G. (1962). Precocious sporulation and longevity of conidia of Helminthosporium sativum in soil. Phytopathology 52, 11721177.

Cole, G. T. (1986). Models of cell differentiation in conidial fungi. Microbiological Reviews 50, 95-132.

CoRTAT, M. \& TuRIAN, G. (1974). Conidiation of Neurospora crassa in submerged culture without mycelial phase. Archiv für Mikrobiologie 85, 305-309. 
Davis, R. H. \& de Serres, F. J. (1970). Genetic and microbiological research techniques for Neurospora crassa. Methods in Enzymology 27A, 79-143.

Dahlberg, K. R. \& Van Etten, J. L. (1982). Physiology and biochemistry of fungal sporulation. Annual Review of Phytopathology 20, 281-301

Daza, A., Martín, J. F., Dominguez, A. \& Gil, J. A. (1989). Sporulation of several species of Streptomyces in submerged cultures after nutritional downshift. Journal of General Microbiology 135, 2483-2491.

Dodge, B. O. (1932). The non-sexual and the sexual functions of microconidia of Neurospora. Bulletin of the Torrey Botanical Club 59, $347-360$.

GeHRiNG, W. J. (1987). Homeoboxes in the study of development. Science 236, 1245-1251.

GrIGG, G. W. (1960). Temperature-sensitive genes affecting conidiation in Neurospora. Journal of General Microbiology 22, 667-670.

Guignard, R., Grange, F. \& Turian, G. (1984). Microcycle conidiation induced by partial nitrogen deprivation in Neurospora crassa. Canadian Journal of Microbiology 30, 1210-1215.

Hennessy, S. W. \& Cantino, E. C. (1972). Lag-phase sporogenesis in Blastocladiella emersoni: induced formation of unispored plantlets. Mycologia 64, 1066-1087.

KLOEPSEL, R. \& ENSIGN, J. C. (1984). Microcycle sporulation of Streptomyces viridochromogenes. Archives of Microbiology 140, 9-14.

KølmarK, H. G. (1985). Mutants with continuous microcycle conidiation in the filamentous fungus Fusarium solani f. sp. pisi. Molecular and General Genetics 198, 12-18.

MAHESHWARI, R. (1989). Asexual reproduction without a mycelial phase in Neurospora. Fungal Genetics Newsletter 36, 48-49.

MAHESHWARI, R. \& ANTONY, A. (1974). A selective technique for the isolation of Neurospora crassa from soil. Journal of General Microbiology 81, 505-507.

Moens, P. B. \& Pearlman, R. E. (1989). Satellite DNA I in chromatin loops of rat pachytene chromosomes and in spermatids. Chromosoma 98, 287-294.

Palanivelu, P. \& Maheshwari, R. (1979). Wild Neurospora isolated from soil. Neurospora Newsletter 26, 15.

Pazantova, S. R., Rehaxex, Z. \& Porkorny, J. (1978). Microcycle sporulation in Claviceps purpurea. Folia Microbiologica 23, 370-378.

Perkins, D. D. (1986). Hints and precautions for the care, feeding and breeding of Neurospora. Fungal Genetics Newsletter 33, 35-41.

Perkins, D. D., Newmeyer, D., Taylor, C. W. \& Bennett, D. C. (1969). New map markers and map sequences in Neurospora crassa, with a description of mapping by duplication coverage, and of multiple translocation stocks for testing linkage. Genetica 40, 247278.

Perkins, D. D., Radford, A., Newmeyer, D. \& Bjorkman, M. (1982). Chromosomal loci of Neurospora crassa. Microbiological Reviews 46, 426-570.

Perkins, D. D., Raju, N. B., Pollard, V. C., Campbell, J. L. \& Richman, A. M. (1986). Use of Neurospora spore killer strains to obtain centromere linkage data without dissecting asci. Canadian Journal of Genetics and Cytology 28, 971-981.

Perkins, D. D. \& TuRner, B. (1988). Neurospora from natural populations: Toward the population biology of a haploid eukaryote. Experimental Mycology 12, 91-131.

Plesofsky-Vig, N., Light, D. \& Brambl, R. (1983). Paedogenetic conidiation in Neurospora crassa. Experimental Mycology 7, 283-286.

RAJU, N. B. (1982). Easy methods for fluorescent staining of Neurospora nuclei. Neurospora Newsletter 29, 24-26.

Rossier, C., Ton That, T. C. \& Turian, G. (1977), Microcyclic microconidiation in Neurospora crassa. Experimental Mycology 1, $52-62$.

Ryan, F. J., Beadle, G. W. \& Tatum, E. L. (1943). The tube method of measuring the growth rate of Neurospora. American Journal of Botany 30, 784-799.

SAVIoUR, R. J. (1981). Microcycle conidiation by Acremonium diospyri in submerged culture. FEMS Microbiology Letters 12, 287-293.

Sekiguchi, J., Gaucher, C. M. \& Costerton, J. W. (1975). Microcycle conidiation in Penicillium urticae. Canadian Journal of Microbiology 21, 2048-2058.

Smith, J. E., Anderson, J. G., Kristiansen, B., Al-Rawi, A. \& YAHYA, A. G. (1981). Microcycle conidiation. In The Fungal Spore: Morphogenetic Controls, pp. 627-650. Edited by G. Turian \& H. R. Hohl. London: Academic Press.

SPRINGER, M. L. \& YANOFSKY, C. (1989). A morphological and genetic analysis of conidiophore development in Neurospora crassa. Genes and Development 3, 559-571.

Ton That, T. C. \& TuRIAN, G. (1978) Ultrastructural study of microcycle macroconidiation in Neurospora crassa. Archives of Microbiology 16, 279-288.

TURIAN, G. (1976). Spores in ascomycetes, their controlled differentiation. In The Fungal Spore: Form and Function, pp. 715-786. Edited by D. J. Weber \& W. M. Hess. New York: John Wiley.

TuRIAN, G. \& BiANCHI, D. E. (1972). Conidiation in Neurospora. Botanical Review 38, 119-154.

UREY, J. C. (1971). Enzyme patterns and protein synthesis during synchronous conidiation in Neurospora crassa. Developmental Biology 26, 17-27.

VAN Gestel, J. F. E. (1983). Microcycle conidiation in Penicillium italicum. Experimental Mycology 7, 287-291.

VOGEL, H. J. (1964). Distribution of lysine pathways among fungi: evolutionary implications. American Naturalist 98, 435-446.

WestergaARD, M. \& Mitchell, H. K. (1947). Neurospora V. A synthetic medium favoring sexual reproduction. American Journal of Botany 34, 573-577.

ZEIDLER, G. \& MarGalith, P. (1973). Modifications of the sporulation cycle in Penicillium digitatum Sacc. Canadian Journal of Microbiology 19, 481-483.

ZUBER, J. \& TURIAN, G. (1981). Induction of premature phialoconidiogenesis on germinated conidia of Trichoderma harzianum. Transactions of the British Mycological Society 76, 433-440. 